\title{
Evaluating the environmental performance of the High Speed Rail project in the Basque Country, Spain
}

\author{
Gorka Bueno $^{\text {a,e,*, }}$, David Hoyos ${ }^{\mathrm{b}, \mathrm{e}}$, Iñigo Capellán-Pérez ${ }^{\mathrm{c}, \mathrm{d}}$
}

Research in Transportation Economics

http://dx.doi.org/10.1016/j.retrec.2017.02.004

${ }^{a}$ Department of Electronics Engineering, Faculty of Engineering, University of the Basque Country UPV/EHU, Alameda Urquijo s/n, 48013 Bilbao, Spain.

${ }^{\mathrm{b}}$ Department of Applied Economics III (Econometrics and Statistics), University of the Basque Country UPV/EHU, Avenida Lehendakari Agirre 83, 48015 Bilbao, Spain.

${ }^{\mathrm{c}}$ Institute of Marine Sciences, ICM-CSIC. Passeig Marítim de la Barceloneta, 37-49, 08003 Barcelona, Catalonia, Spain.

${ }^{\mathrm{d}}$ Research Group on Energy, Economy and System Dynamics, University of Valladolid, Spain.

${ }^{\mathrm{e}}$ EKOPOL, Research Group on Ecological Economics and Political Ecology.

* Corresponding author.

E-mail addresses: gorka.bueno@ehu.eus (G. Bueno), david.hoyos@ehu.eus (D. Hoyos), inigocapell1@gmail.com (I. Capellán-Pérez).

\begin{abstract}
This paper analyses the contribution of the high speed rail project in the Basque Country, Spain, to energy consumption reduction and to climate change mitigation by means of a simplified Life Cycle Assessment. The calculation of $\mathrm{CO}_{2}$ emissions and energy consumption reductions over the service lifetime of the infrastructure (60 years) shows that, even in the most optimistic scenarios considered, it would neither compensate the $\mathrm{CO}_{2}$ emissions linked to its construction and maintenance $\left(2,71 \mathrm{MtCO}_{2}\right)$, nor would it contribute to net energy savings before 55 years of service. Robustness of these results leads us to conclude that GHG emissions reduction and energy savings should not be used as a general argument in favour of investing in high-speed rail infrastructure.
\end{abstract}

Keywords: High-speed rail; Transport policy; Transport hierarchy; Life-cycle assessment; Sustainable mobility;

\section{Highlights}

- Environmental assessment of the new High Speed Rail project in the Basque Country.

- Environmental burdens linked to construction among the highest worldwide.

- Very modest forecast of passengers demand (less than 2.5 million annually).

- The new Basque HSR project does not comply with the Transport Hierarchy.

- GHG emissions reduction cannot be a general argument in favour of new HSR lines.

(C) 2017. This manuscript version is made available under the CC-BY-NC-ND 4.0 license http://creativecommons.org/licenses/by-nc-nd/4.0/ 


\section{Introduction}

Transport policy faces, at the beginning of the twenty-first century, an unresolved dilemma: how to reconcile an apparently unstoppable growth of passenger and freight traffic with its undesirable social and environmentally harmful effects. Transport currently accounts for about a third of EU's energy consumption (European Commission, 2015a) and a fifth of greenhouse gas (GHG) emissions (European Commission, 2015b), and whereas in other sectors GHG emissions have been decreasing, in transport they have grown by $29 \%$ between 1990 and 2009. Moreover, transport activity is expected to double by 2050 (European Commission, 2013, 2011a). Thus, the development of sustainable forms of transport has been one of the key priorities of the transport policy all around Europe. The European Commission, for instance, has repeatedly stressed the need to pursue a series of measures to limit the contribution of transport activity to climate change, calling to strengthen the environmental assessments of policy initiatives with important environmental effects (European Commission, 2011b, 1998).

In this context, high speed rail (HSR) is sometimes proposed as sustainable mode of transport, i.e. as a means to reconcile the dilemma between transport growth and sustainability (see e.g. Jehanno et al., 2011). However, while few countries have embarked in HSR technology, the environmental arguments favouring investments in HSR are far from clear. Railway transport on HSR lines has been acknowledged by the AR5-III (Sims et al., 2014) as an alternative with potential for the reduction of GHG emissions. However, the report highlights that not only the operation, but also the HSR infrastructure construction, maintenance and dismantling produces emissions and other environmental impacts should be considered from an integral perspective of its life-cycle.

The question is, therefore, whether HSR lines can lead to a net reduction of environmental impacts considering their entire life-cycle. Different studies indicate that HSR investments may compensate infrastructure construction burdens and mitigate $\mathrm{CO}_{2}$ emissions (Akerman, 2011; Chang and Kendall, 2011; Chester and Horvath, 2010). However, these reports also underline the high sensitivity of the results to certain variables, such as passengers' demand, traffic diverted and induced and construction burdens. Westin and Kågeson (2012) find that, in order to balance the annual emissions from the railway construction, traffic volumes of over 10 million passengers are needed annually; most of the traffic diverted from other modes must come from aviation, and the lines cannot involve an extensive use of tunnels. Chester and Horvath (2012) estimate that the Californian HSR line (CAHSR, $1100 \mathrm{~km}$ ) might take 6 to 8 years to balance the carbon footprint of construction, provided HSR vehicle occupation is kept higher than for the other transport modes. Chang and Kendall (2011) analyzed the San Francisco-Anaheim line (CAHSR, 725 km) balance, concluding that the GHG emissions footprint could be balanced in 6 years' service, although low occupation might delay the process to over 20 years; and on a line where tunnels and viaducts are only $15 \%$ of the layout. Akerman (2011) likewise defends a net savings on GHG emissions on the Europabanan line (Sweden, $740 \mathrm{~km}$ ). The UIC also claims that the HSR offers tangible advantages over other transport modes (Jehanno et al., 2011).

Furthermore, if the environmental performance of HSR investments is to be evaluated under current European environmental policies (especially regarding climate change and energy consumption), reduction of environmental impacts should not only be undoubted after the infrastructure's lifetime but in a rather shorter period of time. In its Roadmap to a low carbon economy to 2050, the EU has committed to reduce its emissions to at least $80 \%$ below 1990 levels $(40 \%$ by 2030 and $60 \%$ by 2040 ), in order to be consistent with a $+2^{\circ} \mathrm{C}$ temperature stabilisation in comparison to preindustrial levels (European Commission, 2011a). These targets have been accompanied by others such as reducing European energy dependency and reducing the use of critical resources like energy, raw materials, soil and water (European Commission, 2010, 2011c). 
In this context, the Spanish and Basque Governments projected a $180 \mathrm{~km}$ length star-shaped HSR network - commonly known as the Basque Y due to its "Y" shape linking the three Basque capitals- that will also be connected to the French and Spanish HSR lines. The Basque Climate Change Strategy 2050 argues that the construction of this new HSR line would shift transport from other modes and be essential in the reduction of emissions exceeding $80 \%$ on the 2050 horizon. ${ }^{1}$ Strategy Action Line 4 from this Strategy contemplates boosting intermodality and transport means with lower GHG emissions, including a new Basque Railway Network action (\#12) for freight and passenger transport (Basque Government, 2015a). ${ }^{2}$ Actually, the budget of the Basque Government for 2016 allocated the equivalent to over $50 \%$ of the Environment and Territorial Policy Department budget to the HSR construction (Basque Government, 2015b). However, LCA studies of the Spanish HSR network in general (García Álvarez, 2010) and the studies for the Basque Y (Basque Government, 2012) fail to consider the emissions and energy embodied in the construction of the infrastructure, despite the scientific consensus on its importance (Baron et al., 2011; Cour des Comptes, 2014; Sims et al., 2014). In fact, while the Basque Government (2012) reports an emission savings potential of 425 tonnes of $\mathrm{CO}_{2}$ daily for the Basque $\mathrm{Y}$, an assessment of the whole infrastructure life-cycle is still pending.

This paper aims to perform an environmental assessment of the Basque Y HSR project by means of a simplified LCA, in order to specifically analyse its potential contribution to climate change mitigation and energy savings. ${ }^{3}$ The environmental performance of HSR technology is evaluated under two important assumptions: (1) a proper evaluation of the environmental performance of HSR requires considering its entire life-cycle; and (2) the environmental performance in terms of GHG emissions and energy savings should be assessed under current national and European strategies and commitments. In the European context, this means: (1) that GHG emissions should be reduced by $80 \%$ in 2050 as compared to emissions' levels in 1990 (European Commission, 2011a); (2) reducing the use and dependence of energy (European Commission, 2010, 2011c).

The rest of the paper is structured as follows: Section 2 explains the methodology and data used for the simplified life-cycle assessment. Section 3 provides with the results in our baseline scenario and alternative sensitivity scenarios. Section 4 discusses the main findings in the context of the current European transport policy. Finally, Section 5 provides with the main conclusions and policy implications.

\section{Simplified Life Cycle Assessment of the Basque Y}

This section documents the methods and materials to perform a simplified life-cycle assessment (simplified LCA) on the Basque Y HSR infrastructure. Since our aim is to assess its potential

\footnotetext{
${ }^{1}$ The Basque Climate Change Strategy 2050 partially includes the objectives set by the EU. It proposes reducing GHG emissions at least $40 \%$ by 2030 and $80 \%$ by 2050 in relation to 2005 . Furthermore, it proposes achieving $40 \%$ renewable energy contribution in final consumption by 2050. As for the transport sector, the Strategy proposes a reduction in emissions of almost $85 \%$ by 2050.

${ }^{2}$ More specifically, the Basque Climate Change Strategy considers that mobility in the Basque Country will undergo a notable transformation, "firstly, a gradual change from oil derivatives to alternative fuels combined with a drive towards intermodality, fostering modes with lower GHG emissions and boosting pedestrianism in town centres. Subsequently, in the latter decades of the period, where mobility needs will have reduced due to the new territorial and urban planning layout, transport modes like railway and electric cars linked to electricity generation schemes with lower GHG emissions will become consolidated. This transformation will enable transport emissions reductions exceeding $80 \%$ by 2050” (Basque Government, 2015a).

${ }^{3}$ This analysis focuses on the GHG emissions and energy consumption balance; however the reader should bear in mind that other environmental dimensions are also affected by the HSR construction and operation such as: habitat fragmentation, impacts on flora and fauna (affecting biodiversity), occupation of fertile land, landscape and visual impact, noise and vibrations, etc. In fact, impacts are generally similar along road and railways (Cour des Comptes, 2014; Dorsey et al., 2015; Jehanno et al., 2011).
} 
contribution to GHG emissions reductions and energy savings in the context of climate change mitigation and energy security, we focus on calculating the carbon and energy footprint, measured in tonnes of $\mathrm{CO}_{2}\left(\mathrm{tCO}_{2}\right)$ and tonnes of oil equivalent (toe), respectively.

After a brief description of the project background in section 2.1, the steps applied to perform the simplified LCA of the Basque Y in this work are the following: (1) calculation of the carbon and energy footprints associated with the construction and maintenance of the infrastructure (section 2.2.1); (2) calculation of the net carbon and energy footprints associated with operation based on project estimations, considering passengers and freight traffic under a baseline scenario (section 2.2.2); and (3) consideration of four other alternative scenarios for sensitivity analysis (section 2.3).

Any new transportation infrastructure starts from a situation of environmental deficit due to its construction burdens. Thus, a new HSR line may lead to net environmental impact reductions only when the initial deficit is compensated after some years of operation. Since the new infrastructure absorbs demand from other existing transportation modes, the net environmental balance for the new infrastructure is derived from the comparison of environmental impacts from all existing transportation modes in two alternative scenarios, one without the HSR, and the other one with the HSR line in service. Thus, the net environmental impact (EI) of constructing and operating a new HSR line for a generic environmental impact category (e.g. GHG emissions, energy consumption) would be, during year $t$ :

$$
\operatorname{Net} E I(t)=E I_{\text {with } H S R}(t)-E I_{\text {without } H S R}(t)
$$

Environmental impacts in each transport mode can be divided into impacts derived from construction and maintenance (e.g., $E I_{\text {const\&maint }}^{H S R}(t)$ for HSR mode), and impacts derived from operation $\left(E I_{\text {operation }}^{i}(t)\right.$ for a generic mode $\left.i\right)$. These impacts will vary along time, especially in the case of infrastructure construction, which always occurs previous to operation.

Regarding the impacts derived from construction and maintenance of infrastructure for other transport modes different from the new HSR line, as these infrastructures have to be constructed and maintained in both scenarios (with and without the HSR), their net contribution is the one derived from the avoided construction and maintenance linked to the traffic shifted to the HSR, which is assumed to be negligible when compared with the construction and maintenance burdens of the new HSR line. ${ }^{4}$ This way, eq. (1) can be rewritten as:

$$
N e t E I(t)=E I_{\text {const\&maint }}^{\text {HSR }}(t)+\left\{\sum_{i} E I_{\text {operation }}^{i}(t)\right\}_{\text {with HSR }}-\left\{\sum_{i} E I_{\text {operation }}^{i}(t)\right\}_{\text {without HSR }}
$$

$E I_{\text {const\&maint }}^{H S R}(t)$ is estimated in section 2.2.1, and $E I_{\text {operation }}^{i}(t)$ with and without the HSR infrastructure in operation are estimated in section 2.2.2 for each transportation mode $i$.

Thus, at the end of the lifetime of the infrastructure, the total net environmental impact can be estimated as:

$$
=\sum_{\text {yeart }}^{\text {lifetime }} E I_{\text {constemaint }}^{\text {HSR }}(t)+\left\{\sum_{\text {year } t}^{\text {lifetime }} \sum_{\text {mode } i} E I_{\text {operation }}^{i}(t)\right\}_{\text {with HSR }}^{\text {Total Net } E I=}-\left\{\sum_{\text {yeart }}^{\text {lifetime }} \sum_{\text {mode } i} E I_{\text {operation }}^{i}(t)\right\}_{\text {without HSR }}
$$

\footnotetext{
${ }^{4}$ Other studies provide calculations of the avoided burdens linked to avoided maintenance in other modes, which result negligible in comparison to the construction burdens of the new HSR line (more details in section 2.2.2.1); besides, the Basque $\mathrm{Y}$ will shift a small fraction of road traffic from other modes, as will be shown in section 4 .
} 
To perform the assessment, some assumptions have to be made regarding the evolution of the system during the infrastructure lifetime. These assumptions deal with infrastructure lifetime, electrification rate of road passengers transport, decarbonisation rate of the power sector, the type of transport serviced (whether the HSR line transports only passengers, or mixed with freight), transport demand, the induced demand by the new HSR line, vehicle occupation indexes and energy/carbon intensities of transport modes. This analysis considers a baseline scenario which is built assuming the most reasonable technical parameters in the context of the Basque Country and the optimistic demand projections for passengers and freight transport by the Basque administration, as justified in the following section 2.2. Subsequently, in section 2.3, a sensitivity analysis is carried out in order to account for the influence of relevant uncertainties.

For the sake of simplicity, this life-cycle assessment considers constant transport demands and energy intensities for each propulsion technology all over the infrastructure lifetime, in all scenarios.

\subsection{Project background}

With an area of $7,234 \mathrm{~km}^{2}$ (1.4\% of Spanish territory) and around 2.2 million inhabitants (4.6\% of Spanish population), the Basque Country is among the most densely populated regions in Spain. In economic terms, the Basque Country is the second industrial region of Spain and is one of the regions with higher income per capita (31,000 €/cap in 2010, compared to 22,500 €/cap in Spain), contributing $6.3 \%$ to the Spanish GDP. Annual primary energy consumption reached 6,200 ktoe in 2014, of which near 38\% was used for transportation (EVE, 2015).

According to Bueno (2012), passenger transport consumed $66 \%$ of the energy demanded by the transport sector in the Basque Country in 2008, dominated by intraprovincial ${ }^{5}$ journeys $(43 \%)$. International freight transport followed, mainly seaborne, which accounted for $24 \%$ of all energy consumed (Fig. 2 from Bueno (2012)). Current modal split in the Basque Country is dominated by road transport, with rail transport accounting for less than $2 \%$ of freight transport and less than $10 \%$ of passenger transport. Furthermore, the Basque Country has lost $300 \mathrm{~km}$ of railway network in 40 years (1950-1990) despite having doubled its population (Basque Government, 2008). In this context, the Basque $\mathrm{Y}$ is proposed to respond to the railway deficit in the region, being in fact the largest infrastructure ever built in the Basque Country, with a budget of nearly 6,000 million Euros (Basque Government, 2012). ${ }^{6}$

The Basque Y project is a star-shaped European gauge (UIC) HSR covering $180 \mathrm{~km}$ connecting the region's three capitals (Bilbao, Donostia-San Sebastian and Vitoria-Gasteiz, see Figure 1), which total 1.6 million inhabitants. Due to the mountainous orography, $60 \%$ of the layout is through tunnels and $10 \%$ over viaducts. It is planned that the southern point of the star will connect the line to the rest of the Spanish HSR network and the northeast point will connect with the French network, although the date for these connections has yet to be set. This is critical, since other works related to HSR projects have concluded for similar sized regions like Belgium or the Netherlands that domestic demand alone cannot justify a new HSR line (Givoni and Banister, 2012; Kamga and Yazici, 2014).

\footnotetext{
${ }^{5}$ The Basque Country is composed of three provinces, Bizkaia (capital Bilbao), Gipuzkoa (capital Donostia-San Sebastián) and Araba (capital Vitoria-Gasteiz); see Figure 1.

${ }^{6}$ Budget excluding access to the three capitals. Accounting for these might increase the amount to close to 10,000 million Euros (Antigüedad et al., 2016).
} 


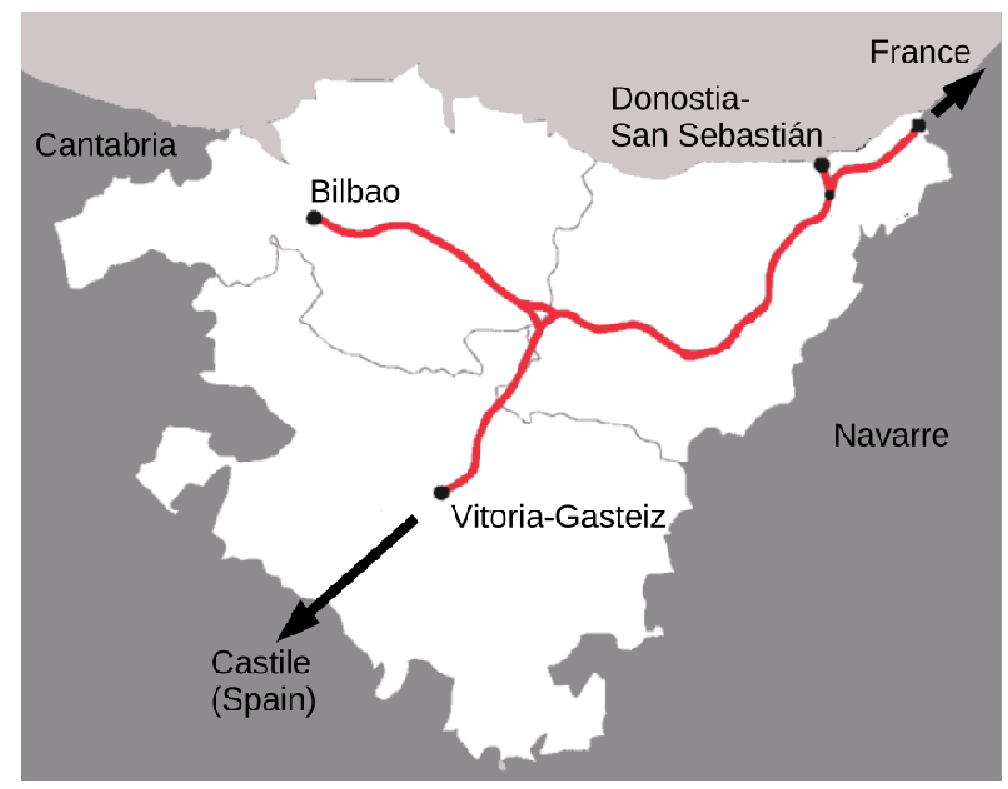

The Basque Y project was passed in 2001 and its construction began in 2006. Although its start-up was initially expected for 2015 (Adif, 2009), various delays have postponed it to beyond 2020 (Antigüedad et al., 2016). Important network elements, such as the entrance layout in the capitals and stations, connections to France and the rest of Spain and its compatibility with freight transport, have yet to be defined. The network has been design to support a combined traffic of passengers $(230-250 \mathrm{~km} / \mathrm{h})$ and freight $(90-110 \mathrm{~km} / \mathrm{h})$. In fact, the scenarios from the Basque Government (2012) attribute the greatest GHG emissions reduction and energy savings potential to freight transport.

\subsection{Calculation of the carbon and energy footprint under the baseline scenario}

The functional unit for this life-cycle assessment is the transport service provided by the HSR infrastructure during one year of operation ( $\mathrm{pkm} / \mathrm{year}$ and $\mathrm{tkm} / \mathrm{year}$ ). This section is divided into two main subsections that calculate the carbon and energy footprint associated with the construction and maintenance of the Basque Y (section 2.2.1) and with its operation (section 2.2.2) for the baseline scenario.

\subsubsection{Carbon and energy footprint associated with HSR construction and maintenance}

The Basque Y will be electrified with $25 \mathrm{kV}$, and has an international gauge double track (1.435 $\mathrm{m})$, laid over plate (on a $14 \mathrm{~m}$ wide platform). The line is designed for combined freight and passengers traffic along which trains will travel with speeds in a range between $90 \mathrm{~km} / \mathrm{h}$ (freight) and $250 \mathrm{~km} / \mathrm{h}$ (passengers). The network connects the three Basque capital cities via a three-pointed star with a total extension of $180 \mathrm{~km}$. The intersection of the three branches is performed in a triangular interchanger of $10 \mathrm{~km}$ on each side with great technical complexity to avoid level crossings on a highly complicated orography. It must be underlined that this star network topology penalizes line exploitation, since any passenger only uses $70 \%$ maximum of the total network extension on each journey though the network. The minimum layout radius is $3.2 \mathrm{~km}(2.2 \mathrm{~km}$ on the interchanger) and the maximum cant is $160 \mathrm{~mm}$. The maximum gradient is 15 thousandths and exceptionally 18 thousandths. 
The mountainous Basque geography greatly hinders the layout adaptation to the terrain, and will require the construction of 23 tunnels and 44 viaducts. Thus, $60 \%$ of the layout runs through tunnels, $10 \%$ over viaducts and only $30 \%$ in open air. The Basque Y will have three main stations in the capitals plus two secondary stations on the branch connecting with France. The construction of two multimodal terminals has also been projected to facilitate freight transport on $750 \mathrm{~m}$ long trains. The network will have four signalling posts, and two overtaking and parking posts. The southern point of the star will connect the line to the rest of the Spanish HSR network and the northeast point will connect the line to the French network, although the Basque Y connection date to the French and Spanish HSR networks has yet to be set.

Our calculation of the burdens associated with the construction of the Basque $\mathrm{Y}$ is based on the lifecycle inventory (LCI) of the HSR infrastructure construction and maintenance included in the Carbon Footprint of the High Speed Rail Report (Baron et al., 2011). This report, sponsored by the International Union of Railways (UIC), estimates the carbon footprint associated with the construction of four HSR lines: "LGV Mediterranée" from Saint-Marcel-lès-Valence to Marseille in France; "South Europe Atlantic-Project" from Tours to Bordeaux in France; the Taipei-Kaohsiung line in Taiwan; and the Beijing-Tianjin line in China.

Table 1 includes the annual carbon footprint corresponding to concepts associated with the Basque Y infrastructure construction and maintenance applying the LCI data of (Baron et al., 2011). In line with that study and others (Akerman, 2011; Botniabanan A.B., 2010), our baseline scenario considers an infrastructure lifetime of 60 years. As other studies have considered this lifetime from 50 years (Sanz et al., 2014) to 100 years (Baron et al., 2011), a sensitivity analysis assuming a 100 year infrastructure lifetime is carried out (SA2, see section 2.3). The burdens associated with track and equipment maintenance are reflected in a lower lifetime consideration for some items (30-50 years) (Baron et al., 2011; Rozycki et al., 2003).

Table 1. Annual carbon footprint of elements and components linked to the construction and maintenance of the Basque $\mathbf{Y}$.

\begin{tabular}{lllll}
$\begin{array}{l}\text { Basque Y } \\
(60 \text { years lifetime })\end{array}$ & $\begin{array}{l}\mathrm{tCO}_{2} \cdot \mathrm{km}^{-1} \text { year }^{-1}, \\
\mathrm{tCO}_{2} \cdot \mathrm{station}^{-1} \text { year }^{-1}\end{array}$ & Units & Lifetime & Total $\left(\mathrm{tCO}_{2}\right.$ year $\left.^{-1}\right)$ \\
\hline Conception & 0.45 & $180 \mathrm{~km}$ & & 81 \\
Earthwork & 37 & $54 \mathrm{~km}$ & 60 years & 1,998 \\
Track construction & 31.6 & $180 \mathrm{~km}$ & 30 years & 5,688 \\
Large viaducts & 305 & $18 \mathrm{~km}$ & 60 years & 5,490 \\
Tunnels & 285 & $108 \mathrm{~km}$ & 60 years & 30,780 \\
Railway equipment & 3.5 & $180 \mathrm{~km}$ & 50 years & 630 \\
Secondary stations & 55 & 2 stations & 60 years & 110 \\
Main stations & 136.7 & 3 stations & 60 years & 410 \\
\hline Basque Y & $251 \mathrm{tCO}_{2} \mathrm{~km}^{-1}$ year $^{-1}$ & $180 \mathrm{~km}$ & & $45,187 \mathrm{tCO}_{2}$ year $^{-1}$ \\
\hline
\end{tabular}

The calculations provide an annual carbon footprint of $251 \mathrm{tCO}_{2} \mathrm{~km}^{-1}$ year ${ }^{-1}$, which lies on the upper end of the 96-270 $\mathrm{tCO}_{2} \mathrm{~km}^{-1}$ range provided by Baron et al. (2011). This means a total carbon footprint of $2.71 \mathrm{MtCO}_{2}$ for the whole infrastructure during its entire lifetime, or $45.19 \mathrm{ktCO}_{2}$ yearly. 
To calculate the energy consumption burdens associated with the Basque $\mathrm{Y}$ construction, we assume an emissions intensity factor $\left(\mathrm{tCO}_{2} /\right.$ toe $)$ coherent with the calculations of other reports which have estimated both the carbon footprint and energy consumption in the construction of other large infrastructures. The LCA for the Bothnia railway line (Sweden, $190 \mathrm{~km}$ ) provides an emissions factor of $4.82 \mathrm{tCO}_{2}$ /toe (Botniabanan A.B., 2010). The construction burdens in the LCA of the "Arroyo Valchano" bridge on the Madrid-Galicia HSR provide a factor of $4.62 \mathrm{tCO}_{2} /$ toe (Acciona Infraestructuras, 2015). Our study assumes an emissions factor of $4.7 \mathrm{tCO}_{2}$ /toe as characteristic of the Basque Y construction, which gives an energy consumption burden associated with the construction of $577 \mathrm{ktoe}(53.4$ toe $/ \mathrm{km})$, or the equivalent to an annual consumption of 9.6 ktoe throughout the infrastructure lifetime.

\subsubsection{Carbon and energy footprint associated with HSR operation}

This section documents the methodology and assumptions to calculate the net carbon and energy footprints associated with the operation of the Basque $\mathrm{Y}$ for passengers and freight. The potential environmental benefits, in terms of energy consumption and GHG emissions, of a new HSR line critically depend on the ability to attract substantial amounts of traffic from other transport modes with high emissions and energy intensity levels. The calculation of the reductions in environmental impacts from the operation of the HSR involves subtracting the impacts of the transport system analyzed with and without the HSR infrastructure (see eq. (2)).

On the one hand, HSR infrastructure start-up leads to transport transfers from other modes; on the other hand, it leads to new induced traffic in the HSR line which is non-existent in the transport system without HSR. The net balance associated with the operation of the infrastructure is the subtraction of the impacts without and with the HSR in service. The environmental impact per transport system is calculated multiplying the transport per mode (e.g. $T_{\text {with } H S R}^{i}(t)$ is the annual transport serviced by mode i expressed in pkm, for passengers transport, and tkm, for freight, in the system with HSR) by the environmental impact coefficients per mode (e.g. in the GHG emissions calculation, $\mathrm{c}^{\mathrm{i}}$ is the GHG emissions factor in grams of $\mathrm{CO}_{2}$ per passenger-kilometre, $\mathrm{gCO}_{2} / \mathrm{pkm}$, or $\mathrm{gCO}_{2} / \mathrm{tkm}$ for freight, of mode $\mathrm{i}$; and grams of oil equivalent per passenger-kilometre, goe/pkm, or goe/tkm for freight, for energy consumption). Thus, eq. (2) can be rewritten as:

$$
\text { Net EI } I_{\text {operation }}(t)=\sum_{i} T_{\text {with } H S R}^{i}(t) \cdot c_{\text {with } H S R}^{i}(t)-\sum_{i} T_{\text {without } H S R}^{i}(t) \cdot c_{\text {without } H S R}^{i}(t) \quad \text { eq. } 4
$$

Figure 2 shows graphically the methodology for a simplified generic case, where an HSR infrastructure provides a complementary transport service to generic transport modes 1 and 2 without and with HSR. 
Figure 2. Graphic representation of transport in generic modes 1 and 2; and HSR in two alternative transport systems, one without HSR (above), and another one with an HSR line in service (below).
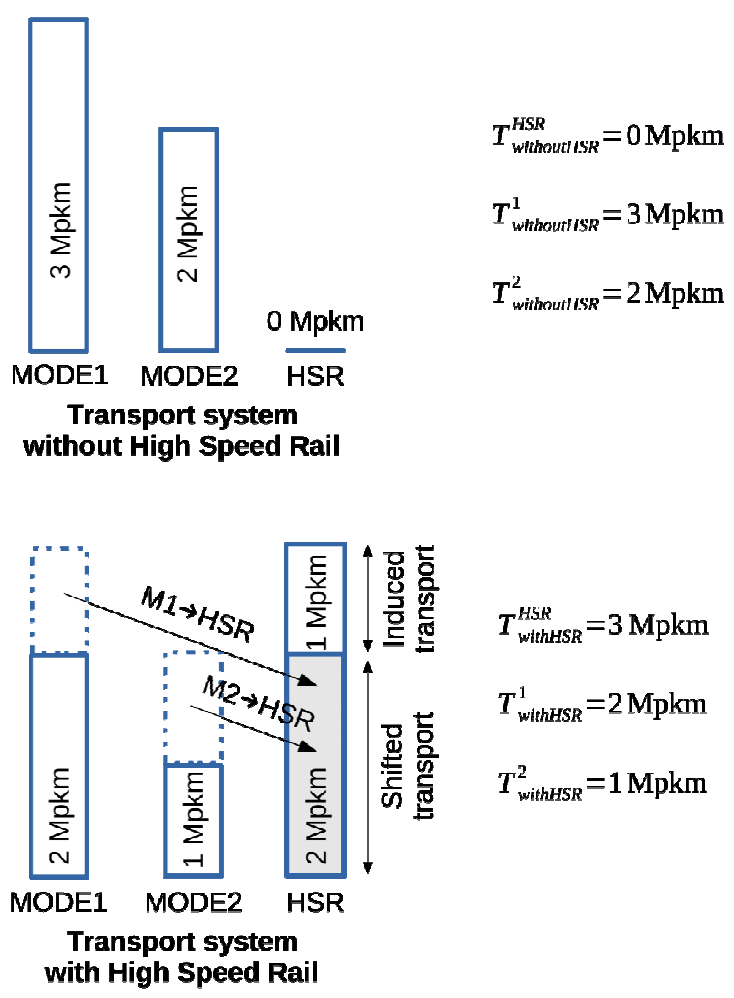

For this simplified case, in a given time t, eq. (4) would be (being $T_{\text {without } H S R}^{H S R}$ zero):

$$
\begin{gathered}
\text { Net EI } I_{\text {operation }}= \\
=T_{\text {with } H S R}^{1} \cdot c_{\text {with } H S R}^{1}+T_{\text {with } H S R}^{2} \cdot c_{\text {with } H S R}^{2}+T_{\text {with } H S R}^{H R} \cdot c^{H S R}-\left(T_{\text {without } H S R}^{1} \cdot c_{\text {without } H S R}^{1}+T_{\text {without } H S R}^{2} \cdot c_{\text {without HSR }}^{2}\right)
\end{gathered}
$$

Assuming that environmental impact coefficients per mode are identical in both scenarios with and without HSR, then eq. (5) can be rewritten as:

$$
\text { Net } E I_{\text {operation }}=\left(T_{\text {with } H S R}^{1}-T_{\text {without } H S R}^{1}\right) \cdot c^{1}+\left(T_{\text {with } H S R}^{2}-T_{\text {without } H S R}^{2}\right) \cdot c^{2}+T_{\text {with } H S R}^{H S R} \cdot c^{H S R}
$$

However, the transport in the HSR line is the sum of transports shifted from the other modes to the HSR $\left(T_{i \rightarrow H S R}^{i}\right)$ plus the induced transport $\left(T_{\text {induced }}^{\text {HSR }}\right)$ :

$$
T_{\text {with } H S R}^{H S R}=\left(T_{\text {without } H S R}^{1}-T_{\text {with } H S R}^{1}\right)+\left(T_{\text {without } H S R}^{2}-T_{\text {with } H S R}^{2}\right)+T_{\text {induced }}^{H S R}=T_{1 \rightarrow H S R}^{1}+T_{2 \rightarrow H S R}^{2}+T_{\text {induced }}^{H S R}
$$

Combining eq. (6) and (7), the net environmental impact in a given time can be rewritten as:

$$
\text { Net } E I_{\text {operation }}=T_{1 \rightarrow H S R}^{1} \cdot\left(c^{H S R}-c^{1}\right)+T_{2 \rightarrow H S R}^{2} \cdot\left(c^{H S R}-c^{2}\right)+T_{\text {induced }}^{H S R} \cdot c^{H S R}
$$

The latter equation can be generalized for $\mathrm{n}$ modes of transportation in any year $\mathrm{t}$ as: 


$$
\text { Net } E I_{\text {operation }}(t)=\sum_{\mathrm{i}}^{\mathrm{i}=\mathrm{n}}\left\{T_{i \rightarrow H S R}^{i}(t) \cdot\left(c^{H S R}(\mathrm{t})-\mathrm{c}^{\mathrm{i}}(\mathrm{t})\right)\right\}+T_{\text {induced }}^{H S R}(t) \cdot c^{H S R}(t)
$$

The net environmental impact derived from the HSR line operation in a given year can therefore be calculated as the sum of transports derived from other modes to the HSR line multiplied by the difference of the transport environmental impact factors in the mode of origin of the diverted transport and in the HSR line, plus the new transport induced in the HSR line multiplied by the environmental impact factor of transport in the HSR line. A negative result in this calculation implies a reduction in environmental impacts derived from the HSR line operation.

This latter formula is very important because it shows not only the potential of HSR lines to reduce certain environmental impacts (when eq. (9) gives a negative result), but also the limits of said reduction. HSR lines can reduce the impact in certain environmental categories provided the HSR transport presents impact coefficients below those of other modes from which diverts traffic (otherwise, eq. (9) cannot give a negative result). This, however, also requires traffic diverted from other modes to present sufficient volume, as the effect of the new induced traffic has to be discounted, too. Actually, it could be the case that the environmental impact linked to the induced transport in the new line might overwhelm the benefits of shifting transport from other modes. In that case, putting the new HSR line into service would not provide a net reduction of overall environmental impacts. It should be added to the foregoing that the HSR infrastructure starts from a situation of environmental deficit due to its construction burdens. The HSR infrastructure leads to net environmental impact reductions only once the initial deficit is compensated, after some years of operation (Westin and Kågeson, 2012).

The remaining of the section documents the sources and methods to estimate the net environmental impact (as given by eq. (9)) of the Basque Y from passengers (section 2.2.2.1) and freight (section 2.2.2.2) transport based on project estimations.

In relation to the technological conditions of transport over such a long period (60 years lifetime), our baseline scenario assumes a dynamic evolution, road passenger transport being progressively electrified and the power system being gradually decarbonised, following the European and Basque energy and climate roadmaps (Basque Government, 2015a; European Commission, 2011a, 2011c). In particular, we consider that road passengers transport will be progressively electrified from 2020 on with an annual increase rate of $15 \%$ until 2050, when $56 \%$ of all road passengers transport would be electrified. Railway transport is currently practically electrified in the Basque Country.

Regarding the decarbonisation of the power sector, our modelling supposes a $10 \%$ annual reduction in the $\mathrm{CO}_{2}$ emissions factor for electricity from 2020 until almost total decarbonisation in 2050, when an emissions factor of $5 \mathrm{gCO}_{2} / \mathrm{MJ}$ is reached. These assumptions are coherent with EU targets and provisions, which consider scenarios where the EU electricity system will be virtually decarbonised by 2050 (European Commission, 2011a) and propose reducing transport emissions 60\% in relation to 1990 (European Commission, 2011c). Meanwhile, the Basque Climate Change 2050 Strategy proposes achieving a renewable energy contribution of $40 \%$ in final consumption by 2050 (Basque Government, 2015a).

The energy and carbon intensities of the different modes of transport, as well as the vehicle occupation indexes are considered constant along all scenarios following the data from (Basque Government, 2012) (see Table 4).

\subsubsection{Passengers transport}

Table 2 shows the annual flow of passengers projected for 2020 for the Basque $Y$ in the optimistic 
demand scenario (scenario B) from Basque Government (2012). ${ }^{7}$ The annual flow of passengers is estimated to reach almost 5 million by 2020 . Since no passenger ever travels the entire $180 \mathrm{~km}$ of the network but rather an average distance of $89.2 \mathrm{~km}$, this corresponds to around 2.45 million passengers per annum over the entire infrastructure layout.

The application of eq. (9) requires knowing which fraction of that transport will be induced and which will come from each of the alternative modes (car, bus, conventional train and air). This information is included in Table 2 and drafted using the scenarios 1-2015 and reference-2013 of Adif (2009), which determines Spanish administration's previsions. These scenarios include passengers transport distribution modes in the reference scenario without the HSR being operational, and in the scenario with the Basque $\mathrm{Y}$ in service. This scenario is, at this moment, the most likely in the long term, since it considers that the HSR line has no connections to Cantabria or Navarre (see Figure 1). However, it does have a complete connection between Vitoria-Gasteiz and Castile/Madrid (Spain), and with France, although the connection with speeds exceeding $200 \mathrm{~km} / \mathrm{h}$ has yet to be decided, and will initially be at a lower speed.

Table 2. Annual passenger flows projected in the Basque $Y$, based on scenario B from Basque Government (2012), shifted and induced transport from other modes to the Basque $Y$, following scenarios 1-2015 and reference-2013 of Adif (2009).

\begin{tabular}{|c|c|c|c|c|c|c|c|c|c|c|}
\hline \multirow[b]{2}{*}{$\begin{array}{l}\text { From } \\
\text { (To) }\end{array}$} & \multirow[b]{2}{*}{$\begin{array}{l}\text { To } \\
\text { (From) }\end{array}$} & \multirow{2}{*}{\begin{tabular}{|l}
$\begin{array}{c}\text { Passengers } \\
\text { (Thous/year) }\end{array}$ \\
HSR
\end{tabular}} & \multirow[t]{2}{*}{$\begin{array}{l}\text { Distance } \\
(\mathrm{km})\end{array}$} & \multicolumn{4}{|c|}{$\begin{array}{l}\text { Shifted transport to the HSR } \\
\text { (Mpkm/year) }\end{array}$} & \multirow{2}{*}{\begin{tabular}{|c|}
$\begin{array}{c}\text { Induced } \\
\text { transport } \\
\text { (Mpkm/year) }\end{array}$ \\
HSR \\
\end{tabular}} & \multirow{2}{*}{\begin{tabular}{|c|}
$\begin{array}{c}\text { Total } \\
(\text { Mpkm/year })\end{array}$ \\
HSR \\
\end{tabular}} & \multirow[t]{2}{*}{$\begin{array}{c}\text { Share } \\
\text { of total } \\
\text { HSR }\end{array}$} \\
\hline & & & & Car & Coach & $\begin{array}{c}\text { Conv. } \\
\text { Rail }\end{array}$ & & & & \\
\hline $\begin{array}{l}\text { Internal } \\
\text { transport }\end{array}$ & & & & & & & & & & $59.5 \%$ \\
\hline Vitoria & Donostia & 569.7 & 105.4 & 32.5 & 11.1 & 11.4 & 0 & 5.0 & 60.0 & $13.6 \%$ \\
\hline Vitoria & Bilbao & $1,113.5$ & 78.5 & 51.5 & 17.4 & 6.9 & 0 & 11.6 & 87.4 & $19.8 \%$ \\
\hline Donostia & Bilbao & $1,031.4$ & 111.4 & 70.9 & 28.7 & 2.8 & 0 & 12.6 & 114.9 & $26.1 \%$ \\
\hline $\begin{array}{l}\text { Medium } \\
\text { distance }\end{array}$ & & & & & & & & & & $7.4 \%$ \\
\hline Vitoria & Castile & 84.4 & 6 & 0.4 & 0.0 & 0.2 & 0 & 0.0 & 0.5 & $0.1 \%$ \\
\hline Donostia & Castile & 142.7 & 111.4 & 6.9 & 1.0 & 7.0 & 0 & 0.9 & 15.9 & $3.6 \%$ \\
\hline Bilbao & Castile & 190.8 & 84.5 & 10.4 & 1.9 & 2.9 & 0 & 1.0 & 16.1 & $3.7 \%$ \\
\hline $\begin{array}{l}\text { Long } \\
\text { distance }\end{array}$ & & & & & & & & & & $33.1 \%$ \\
\hline Vitoria & Madrid & 284.9 & 6 & 1.0 & 0.1 & 0.2 & 0.2 & 0.2 & 1.7 & $0.4 \%$ \\
\hline Donostia & Madrid & 564.7 & 111.4 & 22.4 & 1.6 & 19.7 & 12.6 & 6.5 & 62.9 & $14.3 \%$ \\
\hline Bilbao & Madrid & 959.9 & 84.5 & 33.6 & 4.6 & 5.4 & 24.8 & 12.8 & 81.1 & $18.4 \%$ \\
\hline Total & & $4,942.1 / 2,447.8$ & $89.2 / 180$ & 229.6 & 66.4 & 56.4 & 37.5 & 50.7 & 440.6 & $100 \%$ \\
\hline \multicolumn{4}{|c|}{ Share of shifted transport to the HSR } & $52.1 \%$ & $15.1 \%$ & $12.8 \%$ & $8.5 \%$ & $11.5 \%$ & $100 \%$ & \\
\hline
\end{tabular}

\footnotetext{
${ }^{7}$ This scenario is likewise based on the scenario 1-2015 from Adif (2009).
} 
Additionally, the impact coefficient factors in eq. (9) depend on the evolution of the energy intensities of transport modes, which are considered constant along the lifetime of the HSR infrastructure following the values given by the Basque Government (2012) for all scenarios (see Table 4): 44 goe/pkm for internal combustion engine car transport; 12 goe/pkm for electric car; 9 goe/pkm for bus; 10 goe/pkm for rail transport other than HSR; 41 goe/pkm for air; and 7 goe/pkm for transport by HSR. The $\mathrm{CO}_{2}$ emissions in each transport mode are calculated multiplying the previous energy intensities by the following emissions factors: $108 \mathrm{gCO}_{2} / \mathrm{MJ}$ for electricity, and 74 $\mathrm{gCO}_{2} / \mathrm{MJ}$ for fossil fuel consumption (Bueno, 2012), which provide $138 \mathrm{gCO}_{2} / \mathrm{pkm}$ for car transport, $28 \mathrm{gCO}_{2} / \mathrm{pkm}$ for bus, $45 \mathrm{gCO}_{2} / \mathrm{pkm}$ for conventional rail (electric), $32 \mathrm{gCO}_{2} / \mathrm{pkm}$ for $\mathrm{HSR}$, and $127 \mathrm{gCO}_{2} / \mathrm{pkm}$ for air. Vehicle occupation indexes in all transport modes remain constant all over the period.

For the baseline scenario, a progressive electrification of road transport with an annual increase rate of $15 \%$ until 2050 , where a $56 \%$ of electrification is reached is assumed, as well as a progressive decarbonization of the power sector with a $10 \%$ annual reduction of the electricity emissions factor until almost total decarbonization in 2050. An alternative scenario (SA1) is built assuming a static behaviour of the two latter variables (see Table 4).

Once operational, passengers transport supported by the Basque $\mathrm{Y}$ would be $52.1 \%$ shifted from car transport, $15.1 \%$ from bus, $12.8 \%$ from conventional railway, $8.5 \%$ from air and $11.5 \%$ would be new induced transport. This calculation implicitly supposes that transport diverted to the HSR from other modes corresponds to the same travelling distance within the Basque Country as that which would be using the Basque Y. Although the HSR route may reduce journeys in some cases in relation to the transport mode of origin, it may also require supplementary journeys on public transport to move passengers to and from stations, which added to the HSR journey may compensate and even exceed that of transport in the original mode. Our model has not considered these elements, on the understanding that its global effect compensates and is negligible.

The results from Table 2 allow validating the assumption that the avoided maintenance requirements of the existing infrastructures of the currently operating modes (i.e. car, coach, plane and conventional rail) are negligible comparing with the construction and maintenance burden of the new HSR line. In fact, these loads do not change considerably as a consequence of the commissioning of the HSR, being the diverted traffic from roads just a small fraction of total transport. Besides, the great use of the Basque road network guarantees a small footprint in terms of per passenger-kilometre. As a reference, the AP-8 motorway section in Bizkaia is one which will divert traffic to the Basque Y. In 2013 this section supported a traffic of lightweight vehicles of 9.68 million cars (Interbiak, 2014). An occupation of 1.22 passengers per vehicle (IHOBE, 2006), close to the $30 \%$ observed on other road networks (Sanz et al., 2014), provides an annual transport of 11.8 million people in lightweight vehicles over the entire section, to which we must add freight transport and collective transport on buses. Pursuant to the methodology used by Baron et al. (2011) for the A7 Lyons-Marseille motorway (annual footprint associated with the construction of 73 $\mathrm{tCO}_{2} / \mathrm{km}, 42 \%$ of loads allocated to passengers transport in lightweight vehicles), a carbon footprint associated with construction of just $2.6 \mathrm{gCO}_{2} / \mathrm{pkm}$ is obtained for the AP- 8 motorway. This number is well below the carbon footprint of the Basque $\mathrm{Y}$ of $102.6 \mathrm{gCO}_{2} / \mathrm{pkm}$, which is the result of distributing the emissions burden associated with construction, $251 \mathrm{tCO}_{2}$ per layout kilometre and year, among 2.45 million passengers per year. Akerman (2011) calculates the $\mathrm{CO}_{2}$ emissions prevented on road infrastructures by the Europabanan HSR line (Sweden), assuming burdens associated with construction, maintenance, operation and deforestation, of $78 \mathrm{tCO}_{2} / \mathrm{km}$ annually; under these conditions the burdens avoided by the HSR in the Basque motorway network would also be below $3 \mathrm{gCO}_{2} / \mathrm{pkm}$. 


\subsubsection{Freight transport}

The Basque Government (2012) proposed two freight transport scenarios in the Basque Y operating fully in service by 2020 , one deemed optimistic by the project, and the other more realistic. This paper has assumed the optimistic scenario for the baseline scenario, analysing the realistic one through sensitivity analysis (SA4, see section 2.3). The reference scenario for freight transport in the Basque Country without the HSR uses transport data from year 2010, in which the following adjustments have been made to those considered in (Basque Government, 2012): firstly, for road and rail transport beyond the Basque Country borders (inter-regional and international transport), an average journey length of $100 \mathrm{~km}$ was considered, since that distance is the average that freight travels within the Basque Y geographical area of influence. Impacts or potential reductions associated with HSR transport outside the Basque Country should be attributed to other HSR networks instead of the Basque Y, in this case, the French or other Spanish networks. Secondly, pursuant to the report (Basque Government, 2012), while 3.2 Mt of freight was transported by rail in 2010, the optimistic scenarios foresees moving 3.5 Mt with the HSR, and 8.5 Mt annually with the conventional railway network. That report argues that the diversion of passengers from the conventional network to the Basque $\mathrm{Y}$ would enable road freight transport to be diverted to the conventional railway from other modes. Westin and Kågeson (2012) also point out the beneficial impact the start-up of a new HSR line might have by freeing capacity for freight transport on conventional lines. However, this requires a latent freight transport demand that cannot be covered due to lack of capacity in the conventional network, limited exclusively by passenger transport occupying the entire network. This is not the case of the Basque Country conventional network, since the Basque Government (2008) realizes that freight transport service with the HSR line operational will inevitably also require large investments in the conventional network, such as: the purchase of dual locomotives and polyvalent platforms, construction of twinned rail sections, new train overtaking and stationing sections, freight variants, infrastructure improvement to admit larger loads per axis, improvement of signalling at Orduña Pass (access to the high plains of central Spain), agreements among the different operators in the region; and above all, the construction of the Bilbao South Freight variant. Furthermore, freight related problems in the Bilbao metropolitan area must be solved, the main Basque Country metropolis -entry to and exit from the Port of Bilbao, access to iron and steel yards and several industrial areas. These important conventional network improvements should be considered available in an alternative scenario without the Basque $\mathrm{Y}$, with the corresponding increase in freight transport in the conventional network. As a more straightforward alternative, our scenarios have considered that the conventional railway network transports the same freight flow when the HSR is operative and inoperative, proportionally adjusting the transport in other modes whereby total freight transport remains constant in all scenarios.

Table 3 shows freight transport data considered for the scenarios with the HSR line operational and non-operational for the optimistic (baseline) and realistic (SA4) scenarios. 
Table 3. Annual freight transport data considered for the scenarios with the HSR line operational and non-operational for the optimistic and realistic scenarios, derived from Basque Government (2012).

\begin{tabular}{lllll}
$\begin{array}{l}\text { Transport mode } \\
(\text { data in Mtkm) }\end{array}$ & $\begin{array}{l}\text { Optimistic scenario } \\
\text { No HSR }\end{array}$ & $\begin{array}{l}\text { Optimistic scenario } \\
\text { HSR available }\end{array}$ & $\begin{array}{l}\text { Realistic scenario } \\
\text { No HSR }\end{array}$ & $\begin{array}{l}\text { Realistic scenario } \\
\text { HSR available }\end{array}$ \\
\hline Road & 6,832 & 6,717 & 6,987 & 6,947 \\
Conventional rail & 880 & 880 & 429 & 429 \\
HSR & 0 & 361 & 0 & 176 \\
Air & 10.8 & 10.3 & 11.3 & 11.1 \\
Seaborne & 6,106 & 5,861 & 6,402 & 6,266 \\
\hline Total & 13,829 & 13,829 & 13,829 & 13,829 \\
\hline
\end{tabular}

For the calculations derived from freight transport, our baseline scenario assumes the emissions and energy intensity factors considered in (Basque Government, 2012): $91 \mathrm{gCO}_{2} / \mathrm{tkm}$ and 47.1 goe/tkm for road transport; $19 \mathrm{gCO}_{2} / \mathrm{tkm}$ and $6.8 \mathrm{goe} / \mathrm{tkm}$ for rail transport, both conventional and HSR; 540 $\mathrm{gCO}_{2} / \mathrm{tkm}$ and 754 goe/tkm for transport by air; and $20 \mathrm{gCO}_{2} / \mathrm{tkm}$ and 6.5 goe/tkm for seaborne.

\subsection{Description of scenarios for sensitivity analysis}

The simplified LCA of the Basque Y was performed building a baseline scenario assuming the most reasonable technical parameters and the optimistic demand projections for passengers and freight transport (see section 2.2). In particular, this scenario assumes that the infrastructure will offer mixed freight and passengers transport for a lifetime of 60 years (starting in 2020), a constant transport demand throughout the infrastructure lifetime based on Basque Government's estimations for the year 2020 (Basque Government, 2012), and a dynamic evolution of the technological conditions over the lifetime of the infrastructure for electrification of road passengers transport and decarbonisation of the power system following the European and Basque energy and climate roadmaps (Basque Government, 2015a; European Commission, 2011a, 2011c). Table 4 summarizes the main assumptions of the baseline scenario (for more details see the sections 2.2.1 and 2.2.2).

In order to account for the relevant uncertainties in some of the variables considered, four sensitivity analyses are considered (SA1-4, see Table 4). In each one, a specific variable or hypothesis assumed in the baseline scenario is modified in order to explore its influence in the results. The first sensitivity analysis (SA1) explores the implications of non-compliance of transport electrification and renewability targets, assuming a static scenario where the degree of electrification of transport and of penetration of renewables in the power sector remains constant at current levels. Scenario SA2 extends the infrastructure lifetime to 100 years, coherent with some other assessments in the literature (Baron et al., 2011). An increase of the lifetime of the infrastructure until year 2120 would translate into a decrease of the annual averaged burdens associated to the construction, thus facilitating the potential environmental benefits of the new HSR line. Scenario SA3 considers a situation where the Basque Y infrastructure would transport passengers exclusively, since there are currently serious doubts regarding the commercial and technical viability of combined freight and passengers traffic on the Basque Y (Bermejo and Hoyos, 2016; Ekai Center, 2013). Finally, scenario SA4 considers a moderate demand for freight transport, likewise based on scenarios also considered by the Basque Government (2008). The energy and carbon intensities of the different modes of transport, as well as the vehicle occupation indexes are considered constant along all scenarios.

Table 4 collates the assumptions and characteristics of the baseline and sensitivity scenarios considered in this work. 
Table 4. Characteristics and conditions assumed in the baseline scenario for the simplified LCA, and variations considered in the sensitivity analyses. Conditions Baseline scenario Sensitivity analysis

Progressive electrification of transport

Progressive decarbonisation of the power sector

Infrastructure lifetime

Transport serviced

Passenger transport demand

Freight transport demand

Energy intensities of transport modes

Vehicle occupation indexes
Annual increase rate of $15 \%$ in road passenger transport, SA1 Electrification stable at current levels (residual in road until 2050 (when $56 \%$ of electrification is reached) transport, almost complete by rail)

$10 \%$ annual reduction of the electricity emissions factor SA1 Electricity emissions stable at $108 \mathrm{gCO}_{2} / \mathrm{MJ}$, mean value until almost total decarbonization in 2050

60 years in the Basque Country during the last decade

SA2 100 years

Passenger and freight transport

SA3 Only passenger transport, no freight transport

Following optimistic estimations from (Basque Government, 2012) and scenario \#1 from (Adif, 2009)

Following optimistic estimations from (Basque SA4 Moderate demand scenario from (Basque Government, Government, 2008) 2008)

Those handled in (Basque Government, 2012) :

44 goe/pkm by car, 9 goe/pkm by bus and 47.1 goe/tkm for freight by truck; 10 goe/pkm and 6.8 goe/tkm for conventional rail; 7 goe/pkm and 6.8 goe/tkm for transport by HSR; 41 goe/pkm and 754 goe/tkm for air; and 6.5 goe/tkm for seaborne.

Constant over time

Notes: For each scenario from the sensitivity analysis, all the conditions are the same as for the baseline scenario, excepting for the indicated change. 


\section{Results}

This section outlines the results in terms of potential $\mathrm{CO}_{2}$ and energy savings for the baseline and alternative sensitivity scenarios described in the previous section. It is important to highlight that the baseline scenario is built under the most optimistic transport demand projections of the project.

Firstly, an annual footprint of $251 \mathrm{tCO}_{2} \mathrm{~km}^{-1}$ year $^{-1}$ and 108 toe $\mathrm{km}^{-1}$ year $^{-1}$ for the construction of the Basque Y (including maintenance along its lifetime) are obtained, i.e. the project would start with a footprint of $2.71 \mathrm{MtCO}_{2}$ and $577 \mathrm{ktoe}$. Since this result only depends on the lifetime of the infrastructure, these values only change in the scenario SA2 where a 100-year lifetime is assumed. In this scenario, the environmental burdens linked to construction and maintenance are slightly greater: $2.97 \mathrm{MtCO}_{2}$ of GHG emissions, and 631 ktoe of consumed energy.

In relation to the operation of the infrastructure, from the data shown in Tables 2 and 3 the reduction in energy consumption and emissions associated with the Basque Y project in its first year of operation can be estimated applying eq. (9), considering the emissions and energy intensity factors of the passengers and freight transport modes documented in section 2.1. The results for the baseline scenario are shown in Table 5. For comparison, the last column of Table 5 shows the annual $\mathrm{CO}_{2}$ emissions and energy consumption burdens associated with the construction and maintenance of the infrastructure. The $\mathrm{CO}_{2}$ emissions reduction achieved in the first year of operation of the Basque $\mathrm{Y}$ would only compensate $87 \%$ of the annual carbon footprint associated with the infrastructure construction and maintenance, leaving an annual deficit of $5.9 \mathrm{ktCO}_{2}$. The energy savings derived from HSR passengers transport would compensate the annual energy consumption burden associated with the infrastructure, leaving a net saving of 5 ktoe.

Table 5. Annual reductions of $\mathrm{CO}_{2}$ emissions and energy consumption in the first year of operation of the Basque $\mathrm{Y}$ in the baseline scenario.

\begin{tabular}{lllll} 
& $\begin{array}{l}\text { Passengers } \\
\text { transport }\end{array}$ & $\begin{array}{l}\text { Freight } \\
\text { transport }\end{array}$ & $\begin{array}{l}\text { Passengers and freight } \\
\text { transport }\end{array}$ & $\begin{array}{l}\text { Annual footprint from } \\
\text { construction and maintenance of } \\
\text { infrastructure }\end{array}$ \\
\hline & $440.6 \mathrm{Mpkm}$ & $360.9 \mathrm{Mtkm}$ & $440.6 \mathrm{Mpkm}+360.9 \mathrm{Mtkm}$ & \\
\hline Annual reduction & & & & \\
$\mathrm{CO}_{2}$ emissions & $30.5 \mathrm{ktCO}_{2}$ & $8.81 \mathrm{ktCO}_{2}$ & $39.31 \mathrm{ktCO}_{2}$ & $45.2 \mathrm{ktCO}_{2}$ \\
Energy consumption & $9.64 \mathrm{ktoe}$ & $4.92 \mathrm{ktoe}$ & $14.56 \mathrm{ktoe}$ & $9.6 \mathrm{ktoe}$ \\
\hline
\end{tabular}

Although the baseline scenario assumes that regional transport remains constant throughout the infrastructure lifetime, the progressive penetration of electricity of renewable origin in the transport sector would lead to a progressive change in annual emissions and energy consumption reductions derived from HSR operation along its lifetime. Figure 3 shows the environmental balance of $\mathrm{CO}_{2}$ emissions and energy consumption of the Basque Y throughout the infrastructure lifetime (60 years) for two scenarios: (1) baseline scenario with progressive renewable electrification of transport (solid lines), and an alternative scenario where conditions remain static throughout the infrastructure lifetime (SA1, dashed lines). The environmental burdens associated with the infrastructure construction and maintenance are represented prior to the network service start-up, to reflect the fact that the infrastructure originates from a deficit situation which can only be compensated after functioning a specific number of years. 


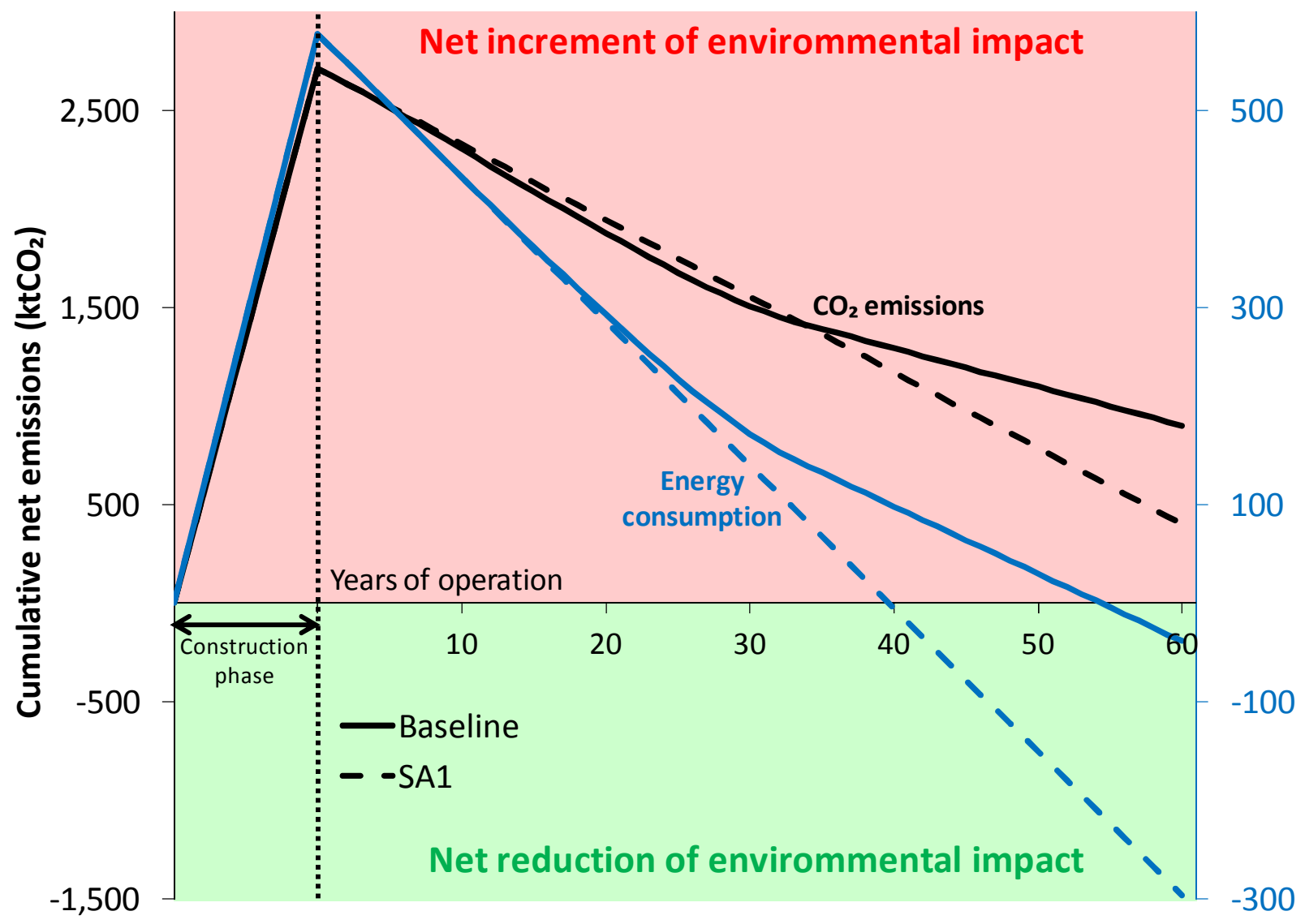

Figure 3 also shows how progressive road transport electrification fed with renewable electricity softens the slope of the curve in the baseline scenario, particularly after 30 years' operation, whereby at the end of the useful infrastructure lifetime the carbon footprint associated with construction is still far from amortization, with a final deficit of around $900 \mathrm{ktCO}_{2}$. As to energy savings, electrification with renewables means compensation of the construction environmental burdens is delayed 15 years in the baseline scenario in relation to the static scenario (SA1), leaving a final net balance of 39 ktoe.

Table 6 shows the final environmental balance at the end of the infrastructure lifetime in relation to net $\mathrm{CO}_{2}$ emission and energy consumption savings, as well as the years of HSR line service required to compensate the environmental burdens associated with the infrastructure construction and maintenance in all the scenarios analyzed. The baseline scenario is the one shown in Figure 3 (solid lines), and is a reference for the other four sensitivity analysis scenarios, where different conditions are modified (see Table 4 in section 2.3): transport electrification and renewable penetration conditions fixed to the initial conditions throughout the infrastructure lifetime (SA1, also shown in Figure 3 with dashed lines); a greater infrastructure lifetime of 100 years (SA2); the Basque Y only transports passengers (SA3); and freight transport demand is adjusted to a more realistic scenario (SA4). 
Table 6. Final environmental balance of scenarios analyzed, baseline (dynamic) scenario and four complementary scenarios for sensitivity analysis.

\begin{tabular}{llllll} 
& & \multicolumn{2}{l}{$\begin{array}{l}\text { Years of service needed to offset } \\
\text { environmental burdens linked to } \\
\text { construction and maintenance of HSR }\end{array}$} & $\begin{array}{l}\text { Net final balance } \\
\text { (negative is net reduction) }\end{array}$ \\
Scenario & Sensitivity analysis & Energy & $\mathrm{CO}_{2}$ emissions & Energy & $\mathrm{CO}_{2}$ emissions \\
\hline Baseline & Reference & 55 years & $>60$ years & $-39 \mathrm{ktoe}$ & $900 \mathrm{ktCO}_{2}$ \\
$\mathrm{SA} 1$ & Static context & 40 years & $>60$ years & $-297 \mathrm{ktoe}$ & $400 \mathrm{ktCO}_{2}$ \\
$\mathrm{SA} 2$ & 100 years lifetime & 63 years & $>100$ years & $-257 \mathrm{ktoe}$ & $370 \mathrm{ktCO}_{2}$ \\
$\mathrm{SA} 3$ & $\begin{array}{l}\text { Only passengers } \\
\text { transport (no freight) }\end{array}$ & $>60$ years & $>60$ years & $308 \mathrm{ktoe}$ & $1.92 \mathrm{MtCO}_{2}$ \\
SA4 & $\begin{array}{l}\text { Realistic freight } \\
\text { transport demand }\end{array}$ & $>60$ years & $>60$ years & $152 \mathrm{ktoe}$ & $1.42 \mathrm{MtCO}_{2}$ \\
& & & & & \\
\hline
\end{tabular}

In terms of GHG emissions, no scenario produces net savings at the end of the lifetime infrastructure, even in the case that its lifetime was extended to 100 years (SA2). Thus, pursuant to the Basque Government's demand previsions, the Basque Y will likely not lead to net reductions of emissions. 3 out of 5 scenarios report negative net energy balance (a net reduction of cumulative energy consumption) at the end of the lifetime infrastructure: baseline, SA1 and SA2. The net energy balance would be barely negative for the baseline scenario (-39 ktoe), taking almost its entire lifetime (55 years) to compensate the environmental burdens associated with construction and maintenance. Non-compliance of transport electrification and renewability targets (static scenario SA1) would allow to save almost 300 ktoe, although this figure represents less than $5 \%$ of current annual primary energy supply in the Basque Country (EVE, 2012). A similar balance would be achieved by extending the infrastructure lifetime to 100 years (SA2, 257 ktoe saved).

In a global context in which rapid emissions reductions are desperately needed in order to restore Earth’s energy balance and avoid irreversible climatic effects (e.g. Hansen et al., 2013), present emissions have more negative climatic impact than future ones, and present reductions have more positive impact than those in the future. As the construction of a new HSR line implies an increase in present emissions to be counterbalanced by future reductions, the consideration of physical carbon discounting rates for emissions and reductions might be alleged. Their calculation, though, is problematic and subject to scientific debate (Baral and Malins, 2014), as it should be based on the analysis of the specific response of climatic models when emissions profiles are moved from the future to present. In any case, the consideration of discounting rates, based on climatic behavior, for $\mathrm{CO}_{2}$ emissions and reductions in the Basque Y HSR project would always worsen an already detrimental net GHG emissions balance. A parallel reasoning could be applied to the energy balance in a context of global increasing fossil energy scarcity.

\section{Discussion}

In this section, we will proceed by discussing the main factors conditioning the results found in the previous section, namely volume of passengers and freight transport and important construction costs and impacts. These results will subsequently be evaluated under current European and Basque energy and climate change commitments as well as sustainable mobility policies.

Firstly, it must be stressed that a volume of transport of 2.45 million passengers per annum over the 
entire infrastructure layout is a magnitude significantly lower than those measured in other railway infrastructures. Table 7 shows the volume of transport and emission burdens associated with several HSR lines around the world.

Table 7. $\mathrm{CO}_{2}$ emissions associated with the construction and maintenance of several HSR lines.

\begin{tabular}{|c|c|c|c|c|c|}
\hline & Reference & $\mathrm{km}$ & $\begin{array}{l}\text { Million annual } \\
\text { passengers }\end{array}$ & $\mathrm{MtCO}_{2}$ & $\mathrm{gCO}_{2} / \mathrm{pkm}$ \\
\hline Basque Y & This work & 180 & 2.45 & 2.71 & 102.6 \\
\hline LGV Mediterranée & (Baron et al., 2011) & 250 & 15.8 & 1.44 & 6.1 \\
\hline South Europe Atlantic-Project & (Baron et al., 2011) & 302 & 15.5 & 1.43 & 5.1 \\
\hline Taipei-Kaohsiung & (Baron et al., 2011) & 345 & 19.9 & 5.59 & 13.6 \\
\hline Beijing-Tianjin & (Baron et al., 2011) & 117 & 23.0 & 1.46 & 9.1 \\
\hline California HSR & (Chester and Horvath, 2010) & 1100 & 24.2 & 9.7 & 6.1 \\
\hline Beijing-Shangai & (Yue et al., 2015) & 1318 & 47.1 & 37.2 & 6.0 \\
\hline Hannover-Wuerzburg & (Rozycki et al., 2003) & 325 & 15.5 & 2.9 & 9.7 \\
\hline Madrid-Barcelona & (Sanz et al., 2014) & 621 & 4 & 6.9 & 46.5 \\
\hline Europabanan & (Åkerman, 2011) & 740 & & 4.0 & \\
\hline San Francisco-Anaheim & (Chang and Kendall, 2011) & 725 & & 2.4 & \\
\hline
\end{tabular}

The emissions burden associated with the construction of the Basque $\mathrm{Y}$ of $251 \mathrm{tCO}_{2}$ per layout kilometre and year, distributed among 2.45 million passengers is equal to a footprint of 102.6 $\mathrm{gCO}_{2} / \mathrm{pkm}$. This burden is one order of magnitude higher than the footprints in other lines, essentially due to the scarce provision of passengers transport demand, i.e. under 2.5 million per annum. Additionally, the technical complexity on many sections of the Basque Y carries with it an important construction carbon footprint, where two thirds correspond to burdens associated with construction of tunnels (60\% of the layout). Under these conditions, the supposed benefit of moving a car passenger (138 $\mathrm{gCO}_{2} / \mathrm{pkm}$, see section 2.1) to the $\mathrm{HSR}\left(32 \mathrm{gCO}_{2} / \mathrm{pkm}\right)$, of $106 \mathrm{gCO}_{2} / \mathrm{pkm}$, is virtually null due to the burden associated with the infrastructure construction $\left(102.6 \mathrm{gCO}_{2} / \mathrm{pkm}\right)$. The burden associated with infrastructure construction can never be ignored; however, as it constitutes a fixed burden, its weight can be significantly reduced in passenger-kilometre terms if a sufficient number of annual passengers can be guaranteed.

Scenarios SA3 and SA4 show the enormous dependence on environmental balance in relation to the freight transport demand. However, today there are serious doubts regarding the commercial and technical viability of combined freight and passenger traffic on the Basque Y (Bermejo and Hoyos, 2016; Ekai Center, 2013). Delving into the freight characterization which the new infrastructure would transport in theory, two elements must be borne in mind; firstly, although the Basque Government (2012) does not stipulate the types of freight considered, the commercial and technical limitations of the mixed HSR transport model leads one to foresee that the HSR would transport high-added value items and packages; and secondly, even in the event of full occupation in the optimistic scenario, the Basque $\mathrm{Y}$ would only transport $5 \%$ of the total current freight traffic, besides bearing in mind that packages currently account for just $4 \%$ of the total (Ekai Center, 2013). In conclusion, the Basque $\mathrm{Y}$ would have (if any) a negligible impact on freight transport.

The importance of freight traffic to improve the environmental balance was already mentioned by Akerman (2011), which pointed out that, in contexts similar to Sweden, new HSR lines (i.e. the 
Europabanan line) may require a large increase in freight transport capacity to justify such important investments. This limits the maximum speed passenger trains can travel at; in the Basque Y case, up to $250 \mathrm{~km} / \mathrm{h}$. The combination of freight and passengers transport improves the network environmental balance by increasing its use. But the passengers transport prevision is almost negligible for the Basque Y, 2.45 million per annum over the entire layout, against a minimum threshold of 10 million passengers proposed by Westin and Kågeson (2012), considering a line with a much shorter tunnel layout (10\%) than the Basque Y (60\%).

To improve its environmental balance, the Basque $\mathrm{Y}$ would have to increase considerably passengers transport diverted from other modes. Table 8 shows in its first row the percentages of transport shifted from other modes and of new induced transport in the Basque $\mathrm{Y}$, to be compared with the percentages of journeys in each mode (second row) that the diverted transport represents in the total within each mode (as per data included in Adif (2009)). Over half the HSR passengers transport would come from car transport (52.1\%); this means, however, transporting only $5.3 \%$ of journeys made by car. HSR would take $8.5 \%$ of its traffic from airplane transport, and as such would take over $41.3 \%$ of all airplane journeys. These data show that the potential of transport increase on the Basque $\mathrm{Y}$ is limited at the expense of long haul transport (air and conventional rail). The greatest potential comes from car journeys; however, the potential of HSR to divert traffic from cars is limited by the fact that, as previously mentioned in section 2.1, the majority of passenger transport in the Basque Country is dedicated to intraprovincial journeys that are out of the scope of the planned HSR line: 73\% of the car journeys made in the Basque Country in 2014 were short haul (OTEUS, 2015). A more efficient alternative to reduce road emissions and energy consumption would be to significantly increase vehicle occupation rates, which would require almost no new infrastructure construction (Bueno, 2012).

Table 8. Origin of transport displaced to HSR and percentage of journeys displaced to HSR within each mode.

\begin{tabular}{llllll} 
& Car & Coach & Conv. Rail & Air & Induced \\
\hline \% of HSR transport shifted from other modes & $52.1 \%$ & $15.1 \%$ & $12.8 \%$ & $8.5 \%$ & $11.5 \%$ \\
\% of journeys shifted from each mode to HSR & $5.3 \%$ & $7.0 \%$ & $55.5 \%$ & $41.3 \%$ & \\
\hline
\end{tabular}

In regards to current transport policy, it is important to highlight the implications of our findings from a sustainable mobility perspective. Although it has been found difficult to provide with an operational definition of sustainable mobility (see e.g. Hoyos, 2009), the transport hierarchy approach has been proposed as a general framework for the assessment of transport policies from a sustainable perspective (Sustainable Development Commission, 2011). Under this framework, the design and management of a HSR investment should follow these four levels of priority: (1) demand minimisation; (2) modal shift and intermodality; (3) efficiency optimisation; and (4) capacity increase. So, given that the creation of a new HSR line ranks last in the hierarchy, robust evidence of positive results in the previous three levels of the hierarchy would be needed in order to consider the construction of a new HSR line as a sustainable mobility policy. This would require that a significant volume of traffic has to be diverted from other less sustainable modes, able not only to overcome the burdens derived from the traffic induced by the new transport offer (which is contrary to the first level of the hierarchy, demand reduction), but also to compensate the environmental impacts linked to the construction of the new infrastructure. Actually, these additional burdens derived from adding new infrastructure to the transport system may significantly reduce, and even overwhelm, benefits derived from modal shift (second level of the hierarchy). Regarding to efficiency (the third level of the hierarchy), although HSR is generally claimed as an 
efficient transport mode, the potential for efficiency improvements in other modes (i.e. the electrification of propulsion or a significant occupancy improvement in private cars) is another option to be checked in a case-by-case analysis (Hoyos et al., 2017).

In respect to modal shift, HSR seems to have had a modest impact in the EU: by doubling the network between 1995 and 2008, HSR has increased its share in the demand for rail from $16 \%$ in 2000 to $24 \%$ in 2008, but the rail network has lowered its modal share from $6.6 \%$ to $6.3 \%$ (Givoni and Banister, 2012). Furthermore, in countries like Spain, investments in HSR are provoking a progressive abandonment of conventional lines (Bermejo and Hoyos, 2016). Finally, although HSR can achieve a remarkable level of energy efficiency in operation, the third level of the transport hierarchy highlights that these efficiency improvements require the traffic to be diverted from less sustainable modes (i.e. air and private cars with low occupation), but not from similarly efficient modes such as bus or conventional train. Furthermore, if dynamic scenarios are considered and overall demand is induced, then the energy arguments favouring investments in HSR are considerably less clear. In this context, the role of the Trans European Network may be controversial: it may favour sustainable mobility by achieving a significant modal shift from road and air to rail, but it may increase overall mobility, so the net effect may be adverse.

Finally, it is also important to contextualise previous results under current European and Basque climate change commitments and targets. Taking into account the magnitude of the environmental problem, as well as the commitments already signed by the EU, the most important contribution of HSR to sustainable mobility lies in its potential for environmental impact reductions, especially with regard to GHG emissions and energy consumption. Given the expected modest (if any) contribution that investing in the Basque $\mathrm{Y}$ would have on emission reduction and energy savings, we can conclude that this investment will not go in favour but against fulfilling the European climate policies' goal of reducing GHG emissions by $80 \%$ by 2050 .

\section{Conclusions}

Supply-side transport policies through massive investments in new transport infrastructures have promoted economic growth and better transport infrastructures over the past half a century, but they have failed to provide net benefits to society due to a series of environmental and socially undesirable effects: congestion, GHG emissions, etc. As a consequence, transport policy in the European Union has struggled between growth as the centrepiece of European treaties and environmental and social protection commitments. However, the indefinite continuation of current trends in transport would be unsustainable in relation to the environmental impact, in particular as regards global warming, as transport is one of the most polluting sectors and its ability to lower its emissions has been somewhat limited. In this uncertain context, HSR infrastructures have been proposed as a means to reconcile the dilemma between transport growth and sustainability due to its potential contribution to energy savings and GHG emissions reductions.

This paper has evaluated the environmental performance of HSR technology in the context of a new project developed in the Basque Country, Spain, under two important assumptions: (1) a proper evaluation of the environmental performance of HSR requires considering its entire life-cycle; and (2) the environmental performance in terms of GHG emissions and energy savings should be assessed under current national and European strategies and commitments. In the European context, this means: (1) that GHG emissions should be reduced by $80 \%$ in 2050 as compared to emissions' levels in 1990 (European Commission, 2011a); (2) reducing the use and dependence of energy (European Commission, 2010, 2011c). 
The environmental burden linked to the Basque $\mathrm{Y}$ construction is estimated at $2.71 \mathrm{MtCO}_{2}$ of GHG emissions and an energy consumption of 577 ktoe. In relative terms, these burdens would be among the highest calculated on HSR lines worldwide, particularly due to the high percentage of tunnels $(60 \%)$ and viaducts $(10 \%)$ in the layout, likewise layout complexity. These environmental burdens linked to construction also place the HSR line environmental balance in a deficit situation initially, at the time of start-up, which would only be compensated after a number of years of line service. The environmental net balance of the Basque Y project is evaluated under different scenarios. The baseline is characterised by a progressive electrification in road passenger transport with optimistic passenger and freight demand projections. Sensitivity analysis is conducted under four scenarios: (1) electrification in road passenger transport remains stable at current levels; (2) infrastructure lifetime is extended from 60 to 100 years; (3) only passenger transport is considered; and (4) moderate transport demand. In terms of GHG emissions, no scenario produces net savings at the end of the lifetime infrastructure, even if the lifetime was extended to 100 years. In regards to energy balance, although some positive results are found, none of the energy savings occurs before 40 years of service (considering the most optimistic scenario). Physical carbon discounting considerations derived from the fact that the functioning of the new HSR line would imply moving $\mathrm{CO}_{2}$ emissions and energy consumption from the future to present would only worsen these already detrimental balances. Hence, according to our analysis, the Basque Y project does not seem to contribute to compliance with regional, national and European energy and climate targets, and even moves away from them. Therefore, high construction and operation costs drag not only financial and social profitability of this project, as argued by Hoyos and Bel (2016), but also its environmental accounting.

These results are found to be highly dependent on the volume of transport and the consideration of freight transport. When evaluated under the transport hierarchy framework, we conclude that this new infrastructure does not contribute to sustainable mobility: firstly, because the Basque Y project implies a transport capacity increase (i.e. last level of the hierarchy), which will induce new transport (contrary to the first level of the hierarchy, demand minimization); secondly, because it will shift a very modest traffic flux from less sustainable modes that may even not compensate environmental burdens linked to construction (also contrary to the second level of the hierarchy, modal shift to more sustainable modes); and thirdly, because it provides efficiency improvements that are not unreachable in the context of the Basque Country for other transport modes, in application of the third level of the transport hierarchy (efficiency optimization, i.e. renewable electrification of private cars, or the increase of vehicle occupancy). For example, policies directed towards significantly increasing occupancy rates (1.22 passengers per private vehicle) would not only reduce GHG emissions and save energy, but also allow for moderate increases in other efficient transport niches.

Robustness of these results leads us to conclude that GHG emissions reduction and energy savings should not be used as a general argument in favour of investing in HSR infrastructures. Furthermore, considering European ambitious climate and energy goals and that transport operation accounts for one third of EU-28's final energy consumption and one fifth of the total GHG emissions, HSR net environmental benefits (if any) may not be cost-efficient given the massive financial investment they require.

\section{Acknowledgements}

Financial support by the University of the Basque Country (UPV/EHU) under research grants UFI11/03 and US15/11, by the Department of Education of the Basque Government through Grant IT-642-13 (UPV/EHU Econometrics Research Group) and by the Spanish Ministry of Economy and Competitiveness through grant ECO2014-52587-R is gratefully acknowledged. 


\section{Bibliography}

Acciona Infraestructuras, 2015. EPD Railway bridge on the Madrid-Galicia North-Northwest highspeed line [WWW Document]. URL http://gryphon.environdec.com/data/files/6/9343/S-EP00455_Acciona_Railway_bridge.pdf

Adif, 2009. Estudio de mercado de viajeros y rentabilidad económico-social y financiera de la Línea de Alta Velocidad Madrid-Norte y País Vasco.

Akerman, J., 2011. The role of high-speed rail in mitigating climate change - The Swedish case Europabanan from a life cycle perspective. Transp. Res. Part Transp. Environ. 16, 208-217. doi:10.1016/j.trd.2010.12.004

Antigüedad, I. et al., 2016. Análisis transdisciplinar del modelo ferroviario de alta velocidad: El proyecto de nueva Red Ferroviaria para el País Vasco, Cuadernos de Hegoa 71; Bilbao, 2016; http://publicaciones.hegoa.ehu.es/assets/pdfs/355/Lan_Koadernoa_71.pdf?1483098132

Baral, A., Malins, C., 2014. Comprehensive carbon accounting for identification of sustainable biomass feedstocks. Washington, DC: The International Council on Clean Transportation; http://www.theicct.org/comprehensive-carbon-accounting-identification-sustainablebiomass-feedstocks

Baron, T., Martinetti, G., Pépion, D., 2011. Carbon footprint of high speed rail. International Union of Railways (UIC), Paris.

Basque Government, 2015a. Estrategia de Cambio Climático 2050 del País Vasco. Gobierno Vasco, Vitoria-Gasteiz.

Basque Government, 2015b. Presupuestos Generales de la Comunidad Autónoma de Euskadi [WWW Document]. URL

http://www.euskadi.eus/k28aVisWar/k28aGenVis.jsp?doc=/presupuestos/2016_A/volumene s/01/01.BOOK.pdf\&tipo=1\&nombreDoc=Argibide\%20Memoria\%20-

\%20Memoria\%20Explicativa.pdf (accessed 5.24.16).

Basque Government, 2012. La Y Vasca: Un proyecto de País, una conexión internacional, Gobierno Vasco. ed. Vitoria-Gasteiz.

Basque Government, 2008. Incidencia de la nueva red ferroviaria de ancho internacional en el transporte de mercancías por ferrocarril en el País Vasco, Departamento de Transportes y Obras Públicas, Vitoria-Gasteiz.

Bermejo, R., Hoyos, D., 2016. Análisis del origen y desarrollo del proyecto de Y vasca en el contexto de la política europea de transporte, in: Antigüedad, I. et al., Análisis transdisciplinar del modelo ferroviario de alta velocidad: El proyecto de nueva Red Ferroviaria para el País Vasco, Cuadernos de Hegoa 71; Bilbao, 2016; http://publicaciones.hegoa.ehu.es/assets/pdfs/355/Lan_Koadernoa_71.pdf?1483098132

Botniabanan A.B., 2010. Environmental Product Declaration for the railway infrastructure on the Bothnia Line, Reg. no. S-P-0019. UN CPC 5321.

Bueno, G., 2012. Analysis of scenarios for the reduction of energy consumption and GHG emissions in transport in the Basque Country. Renew. Sustain. Energy Rev. 16, 1988-1998. doi:10.1016/j.rser.2012.01.004

Chang, B., Kendall, A., 2011. Life cycle greenhouse gas assessment of infrastructure construction for California's high-speed rail system. Transp. Res. Part Transp. Environ. 16, 429-434. doi:10.1016/j.trd.2011.04.004

Chester, M., Horvath, A., 2010. Life-cycle assessment of high-speed rail: the case of California. Environ. Res. Lett. 5, 14003. doi:10.1088/1748-9326/5/1/014003

Cour des Comptes, 2014. La grande vitesse ferroviaire: un modèle porté au-delà de sa pertinence (Rapport public thématique). Cour des Comptes, Paris, France.

Dorsey, B., Olsson, M., Rew, L.J., 2015. Ecological Effects of Railways on Wildlife, in: Ree, R. van der, Smith, D.J., Grilo, C. (Eds.), Handbook of Road Ecology. John Wiley \& Sons, Ltd, pp. 219-227. 
Ekai Center, 2013. Evaluación económica de la Y vasca. Ekai Center, Innovating Public Policy, Mondragón.

European Commission, 2015a. EU energy in figures. Statistical pocketbook 2015. European Commission, Brussels.

European Commission, 2015b. EU transport in figures. Statistical pocketbook 2015. European Commission, Brussels.

European Commission, 2013. EU energy, transport and GHG emissions - trends to 2050: reference scenario 2013. European Commission, Luxembourg.

European Commission, 2011a. A Roadmap for moving to a competitive low carbon economy in 2050 (No. COM (2011) 112 final). Communication from the Commission to the European Parliament, the Council, the European Economic and Social Committee and the Committee of the Regions, Brussels.

European Commission, 2011b. White Paper. Roadmap to a single European transport area - towards a competitive and resource efficient transport system (No. COM (2011) 144 final). European Commission, Brussels.

European Commission, 2011c. Roadmap to a Resource Efficient Europe (No. COM (2011) 571 final). European Commission, Brussels.

European Commission, 2010. Critical raw materials for the UE. Report of the Ad-hoc Working Group on defining critical raw materials. European Commission.

European Commission, 1998. The Common Transport Policy. Sustainable Mobility: Perspectives for the Future. Follow-up to the Green Paper. COM (98) 716 final/2, 21 December 1998. European Commission, Brussels.

EVE, 2015. Euskadi Energía 2014. Datos energéticos. Ente Vasco de la Energía, Bilbao.

EVE, 2012. Estrategia energética de Euskadi 2020. Ente Vasco de la Energía, Bilbao.

García Álvarez, A., 2010. Energy Consumption and Emissions of High-Speed Trains. Transp. Res. Rec. J. Transp. Res. Board 2159, 27-35. doi:10.3141/2159-04

Givoni, M., Banister, D., 2012. Speed: the less important element of the High-Speed Train. J. Transp. Geogr., Special Section on Rail Transit Systems and High Speed Rail 22, 306-307. doi:10.1016/j.jtrangeo.2012.01.024

Hansen, J., Kharecha, P., Sato, M., Masson-Delmotte, V., Ackerman, F. et al., 2013. Assessing "Dangerous Climate Change': Required Reduction of Carbon Emissions to Protect Young People, Future Generations and Nature. PLoS ONE 8(12): e81648. doi:10.1371/journal.pone.0081648

Hoyos, D., 2009. Towards an operational concept of sustainable mobility. Int. J. Sustain. Dev. Plan. 4, 158-173. doi:10.2495/SDP-V4-N2-158-173

Hoyos, D., Bel, G., 2016. Evaluación económica del proyecto de Y vasca, in: Antigüedad, I. et al., Análisis transdisciplinar del modelo ferroviario de alta velocidad: El proyecto de nueva Red Ferroviaria para el País Vasco, Cuadernos de Hegoa 71; Bilbao, 2016; http://publicaciones.hegoa.ehu.es/assets/pdfs/355/Lan_Koadernoa_71.pdf?1483098132

Hoyos, D., Bueno, G., Capellán-Pérez, I., 2017. Environmental assessment of high-speed rail, in: Albalate, D., Bel, G. (Eds.), Evaluating High-Speed Rail. Interdisciplinary Perspectives, Routledge Studies in Transport Analysis. New York.

IHOBE, 2006. TRANSPORTE Y MEDIO AMBIENTE EN LA COMUNIDAD AUTÓNOMA DEL PAÍS VASCO. INDICADORES TMA 2007.

Interbiak, 2014. La AP 8 en cifras 2013 - La AP 8 en cifras 2013.pdf [WWW Document]. URL http://interbiak.bizkaia.net/fitxategiak/dokumentuak/File/UserFiles/file/publicaciones/La\%2 0AP\%208\%20en\%20cifras\%202013.pdf (accessed 9.14.15).

IPCC, 2014. Climate Change 2014 Mitigation of Climate Change Working Group III Contribution to the Fifth Assessment Report of the Intergovernmental Panel on Climate Change.

Jehanno, A., Palmer, D., James, C., 2011. High Speed Rail and Sustainability.

Kamga, C., Yazici, M.A., 2014. Achieving environmental sustainability beyond technological improvements: Potential role of high-speed rail in the United States of America. Transp. 
Res. Part Transp. Environ. 31, 148-164. doi:10.1016/j.trd.2014.06.011

OTEUS, 2015. Panorámica del transporte en Euskadi, 2014. Gobierno Vasco, Vitoria-Gasteiz.

Rozycki, C. von, Koeser, H., Schwarz, H., 2003. Ecology profile of the german high-speed rail passenger transport system, ICE. Int. J. Life Cycle Assess. 8, 83-91. doi:10.1007/BF02978431

Sanz, A., Vega, P., Mateos, M., 2014. Las cuentas ecológicas del transporte en España. Libros en Acción, Madrid.

Sims, R., Schaeffer, R., Creutzig, F., Nunez, X., D’Agosto, M., Dimitriu, D., Meza, M., Fulton, L., Kobayashi, S., Lah, O., McKinnon, A., Newman, P., Ouyang, M., Schauer, J.J., Sperling, D., Tiwari, G., 2014. Chapter 8: transport. Mitig. Contrib. Work. Group III Fifth Assess. Rep. Intergov. Panel Clim. Change.

Sustainable Development Commission, 2011. Fairness in a Car-dependent Society. Sustainable Development Commission, London.

Westin, J., Kågeson, P., 2012. Can high speed rail offset its embedded emissions? Transp. Res. Part Transp. Environ. 17, 1-7. doi:10.1016/j.trd.2011.09.006

Yue, Y., Wang, T., Liang, S., Yang, J., Hou, P., Qu, S., Zhou, J., Jia, X., Wang, H., Xu, M., 2015. Life cycle assessment of High Speed Rail in China. Transp. Res. Part Transp. Environ. 41, 367-376. doi:10.1016/j.trd.2015.10.005 